\title{
Avaliação Qualitativa da Pastagem Diferida de Brachiaria decumbens Stapf., sob Pastejo, no Período da Seca, por Intermédio de Três Métodos de Amostragem
}

\author{
Eduardo Henrique Bevitori Kling de Moraes', Mário Fonseca Paulino², Joanis Tilemahos \\ Zervoudakis $^{3}$, Sebastião de Campos Valadares Filho ${ }^{2}$, Kamila Andreatta Kling de Moraes ${ }^{4}$
}

\begin{abstract}
RESUMO - O experimento foi conduzido para avaliar a qualidade da pastagem diferida de Brachiaria decumbens sob pastejo durante o período da seca, utilizando-se quatro novilhos Holandês-Zebu fistulados no esôfago. As amostras foram coletadas com base na disponibilidade total (DT), na simulação manual de pastejo (SMP) e na extrusa (EXT) coletada. Foram determinados os teores de matéria seca (MS), proteína bruta (PB), extrato etéreo (EE), matéria mineral (MM), carboidratos totais (CT) e não-fibrosos (CNF), fibra em detergente neutro (FDN), fibra em detergente neutro isenta de cinzas e proteínas (FDNcp), fibra em detergente ácido (FDA), fibra em detergente ácido indigestível (FDAi), lignina e digestibilidade in vitro da matéria seca (DIVMS). As amostras obtidas com a DT apresentaram valores superiores para MS, CT, FDN, FDNcp, FDA, FDAi e lignina, que refletiram na menor DIVMS para a DT. A EXT e a SMP não diferiram quanto à PB, EE, CNF, FDN, FDNcp, FDA, FDAi, lignina e DIVMS. Os teores de PB foram 5,60 e 6,50 e os de FDN foram 71,87 e 71,70, respectivamente, para a SMP e a EXT. Os resultados sugerem que a amostra obtida pela SMP, em comparação com a DT, estaria mais próxima da forragem selecionada por animais em pastejo.
\end{abstract}

Palavras-chave: bovino de corte, disponibilidade total, extrusa, simulação de pastejo

\section{Qualitative Evaluation of differed pasture of Brachiaria decumbens Stapf., Under Grazing, in the Dry Season, Using Three Sampling Methods}

\begin{abstract}
An experiment was conducted to evaluate the quality of the differed pasture of Brachiaria decumbens under grazing in the dry season. Samples were collected by the total harvesting (TH), hand-plucking sample (HPS) and Extrusa (EXT) collected using four Holstein-Zebu steers, with esophageal fistula. The samples were analysed for dry matter content (DM), crude protein (CP), ether extract (EE), mineral matter (MM), total (TC) and non-fibrous carbohydrates (NFC), neutral detergent fiber (NDF), neutral detergent fiber corrected for ash and protein (NDFap), acid detergent fiber (ADF), insoluble acid detergent fiber (iADF), lignin and in vitro dry matter digestibility (IVDMD). TH was superior $(\mathrm{P}<0,05)$ in DM, TC, NDf, NDFap, ADF, iADF and lignin contents. These observations reflected the low IVDMD for TA. The EXT and HPS did not differ on CP, EE, NFC, NDF, NDFap, ADF, iADF, lignin and IVDMD. The CP content were 5.60 and 6.50 and the ones of NDF were 71.87 e 71.70, respectively to EXT and HPS. These results indicate that the sample HPS, in comparasion with sample TH, would better represent those diet selected by grazing animals.
\end{abstract}

Key Words: beef cattle, extrusa, hand-plucking sample, total harvesting

\section{Introdução}

No Brasil, a bovinocultura de corte é fortemente sustentada pelas forrageiras, sobretudo a Brachiaria decumbens, tornando-as principal fonte de nutrientes para animais em pastejo. Neste contexto, enfatiza-se a importância dos conceitos de valor nutritivo e de valor alimentício das forrageiras (Gomide \& Queiroz, 1994).

A produção animal em sistemas de pastejo exclusivo é determinada pelo consumo e pela disponibilidade de matéria seca tendo como parâmetro mais importante na avaliação de pastagens o seu valor nutritivo, que apresenta alta correlação com a produção animal (Noller et al., 1997). Sob pastejo, o consumo de matéria seca verde é afetado principalmente pela disponibilidade de forragem, acompanhada pela estrutura da vegetação (densidade, altura, relação folha-colmo).

Várias pesquisas com bovinos em pastejo têm sido realizadas para o aperfeiçoamento da determinação da qualidade da forragem ingerida pelos animais nestas condições. No entanto, poucos são os dados oriundos de pastagens diferidas, embora sejam amplamente utilizadas, visando amenizar a carência de massa forrageira durante a estação seca do ano, quando ocorre redução no crescimento das plantas (Paulino et al., 2003).

\footnotetext{
1 Zootecnista, MS, Estudante de Doutorado, DZO-UFV, Viçosa-MG (ehbkm@yahoo.com.br). Bolsista do CNPq

2 Professor do DZO, UFV, Viçosa-MG, 36570-000.

3 Zootecnista, DS, Professor, Depto. de Zootecnia e Extensão Rural, UFMT, Cuiabá-MT.

${ }^{4}$ Zootecnista, Estudante de Mestrado, DZO - UFV.
} 
Todavia, essas pastagens apresentam boa disponibilidade de forragem, com baixo valor nutritivo, exigindo que o diferimento esteja sempre associado à suplementação alimentar, possibilitando níveis aceitáveis de desempenho dos animais no período seco do ano. Entretanto, para que isto ocorra com eficiência, é necessário o conhecimento da composição bromatológica desta macega.

No método de coleta pela disponibilidade total (DT) de matéria seca, em que se considera toda a planta, tem-se observado que as amostras da forragem normalmente não são representativas da dieta ingerida pelos animais (Euclides et al., 1992 e Goes et al.,2003). No entanto, em um pasto de baixa qualidade, verifica-se o esforço do animal em selecionar uma forragem de melhor valor nutritivo (partes verdes, principalmente as folhas), superior à forragem disponível na pastagem.

O uso de animais fistulados no esôfago permite a coleta de boas amostras da forragem pastejada (Euclides et al., 1992). Contudo, Jones \& Lascano (1992) afirmam que o uso de animais fistulados pode fornecer estimativas errôneas do valor nutritivo da forragem selecionada por animais "residentes" (que estão permanentemente no experimento), devendo-se considerar a possibilidade de contaminação por nitrogênio salivar ou a perda de materiais solúveis, o que pode alterar a digestibilidade e a exatidão das análises (Minson et al., 1976). Adicionalmente, o curto tempo de pastejo para a obtenção das amostras pode torná-las não-representativas da forragem consumida durante todo o período de pastejo (McMeniman, 1997).

Neste contexto, a utilização da simulação manual de pastejo (SMP) tem sido indicada como um método viável (Euclides et al., 1992; De Vries, 1995 e Goes et al., 2003), tanto por sua representabilidade quanto pela praticidade. Segundo Pedreira (2002), para melhorar a representabilidade da SMP, é necessário identificar, antes da amostragem, o hábito de pastejo dos animais. Em estudos comparando a extrusa com a SMP, foram observados maior teores de proteína bruta (Hafley et al., 1993) e cinzas (Kiesling et al., 1969) para a extrusa. Detmann et al. (1999) afirmam que a utilização da SMP levaria à obtenção de valores subestimados do consumo de matéria seca, quando utilizado seu teor de FDNi como indicador interno, em comparação à extrusa esofágica.
Avaliou-se, neste estudo, o valor nutritivo de amostras de Brachiaria decumbens diferida sob pastejo, na estação seca, coletadas segundo três métodos de amostragem.

\section{Material e Métodos}

O experimento foi realizado na Central de Experimentação, Pesquisa e Extensão do Triângulo Mineiro (CEPET) da UFV, durante a estação seca, de julho a setembro de 2001. Aárea experimental da pastagem constituiu-se de quatro piquetes de 0,5 ha cada, cobertos uniformemente com Brachiaria decumbens Stapf., diferida, providos de bebedouros e cochos. O sistema de pastejo adotado foi o contínuo, com um animal fistulado no esôfago alocado em cada piquete. Os animais foram rotacionados entre os piquetes a cada sete dias visando reduzir possíveis efeitos de disponibilidades de MS nos piquetes experimentais.

Na Figura 1, encontram-se os dados climáticos (precipitação total, temperaturas máxima e mínima) registrados no período experimental.

Os métodos de amostragem avaliados foram coleta da disponibilidade total da pastagem (DT), extrusa e simulação manual do pastejo (SMP). As coletas da forragem foram realizadas, todas no mesmo dia, a cada 30 dias em cada piquete experimental.

$\square \operatorname{Tmín}\left({ }^{\circ} \mathrm{C}\right) \square \operatorname{Tmáx}\left({ }^{\circ} \mathrm{C}\right) \square \mathrm{PP}(\mathrm{mm})$

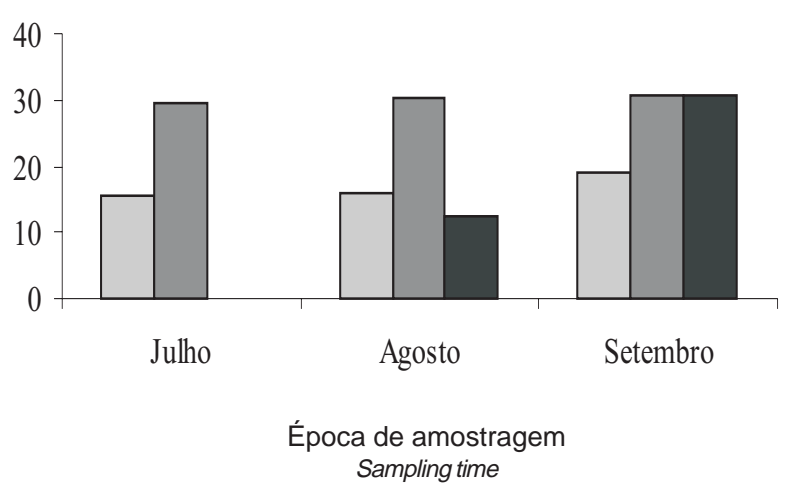

Figura 1 - Temperaturas mínima (Tmín) e máxima (Tmáx) e precipitação total (PP) no período experimental. Fonte: CEPET/UFV.

Figure 1 - Minimun and maximum temperatures and total rainfall, in the experimental periods. Source: CEPET/UFV. 
Efetuou-se a coleta da DT nos diferentes piquetes por meio do corte rente ao solo, em cinco áreas delimitadas por um quadrado metálico de $0,5 \times 0,5 \mathrm{~m}$, escolhidas aleatoriamente em cada piquete experimental, segundo McMeniman (1997). Após a pesagem, cada amostra foi homogeneizada, retirando-se duas subamostras compostas, uma para avaliação da disponibilidade total de matéria seca/ha e composição bromatológica e outra para análise da disponibilidade de matéria seca verde/ha em cada piquete experimental.

Para a coleta da extrusa, utilizaram-se quatro novilhos Holandês-Zebu, castrados, com peso médio de $460 \mathrm{~kg}$, fistulados no esôfago. Os animais receberam suplementos múltiplos (Moraes et al., 2003) e ficaram em jejum por 12 horas no dia anterior à coleta, para se garantir o consumo do pasto (Forbes, 1993) e evitar a contaminação por material regurgitado do rúmen (McMeniman, 1997). A coleta de extrusa foi realizada às $7 \mathrm{~h}$, com auxílio de bolsas coletoras com fundo telado, adaptadas em torno da fístula no pescoço dos animais, que foram conduzidos aos seus respectivos piquetes por 20-30 minutos. Após o pastejo, foram recolhidas amostras por cada animal seqüencialmente reduzidas a uma amostra composta única por coleta.

O método da SMP foi realizado conforme Johnson (1978), identificando-se o tipo de material consumido e coletando-se uma amostra semelhante ao alimento ingerido. A coleta foi realizada por um único amostrador em todo o período experimental, a fim de se evitar variações em cada amostragem.

Após as coletas, pelos três métodos, realizou-se a pré-secagem das amostras em estufa ventilada, por 72 horas, sendo posteriormente processadas em moinho com peneira de malha de 1,0 mm e acondicionadas em potes de plástico. Foram determinados os teores de matéria seca (MS), nitrogênio total (N), extrato etéreo (EE), cinzas, fibra em detergente neutro (FDN), fibra em detergente neutro isenta de cinzas e proteína (FDNcp), fibra em detergente ácido (FDA), fibra em detergente ácido indigestível (FDAi) e lignina. Com exceção das análises de FDN e FDA, feitas segundo Van Soest (1991), as demais análises seguiram as recomendações de Silva \& Queiroz (2002).

A determinação da digestibilidade in vitro da matéria seca (DIVMS) foi realizada conforme a técnica de Tilley \& Terry (1963). Os carboidratos totais (CT) foram obtidos pela equação: 100 - (\% PB + \%EE + \%Cinzas) (Sniffen et al., 1992), os carboidratos não- fibrosos (CNF), pela diferença entre CT e FDNcp e a FDAi, pela metodologia descrita por Cochran et al. (1986).

Utilizou-se o Sistema de Análises Estatísticas e Genéticas - SAEG (UFV, 2000), para análise dos resultados, e o teste de Student Newman-Keuls (SNK) a 5\% de significância, para comparação das médias.

\section{Resultados e Discussão}

Na Figura 2, são apresentadas as disponibilidades estimadas de matéria seca total (MST) e matéria seca verde (MSV) do pasto nos diferentes períodos de coleta. As disponibilidades de MST e MSV médias foram, respectivamente, de 5.560 e $1.515 \mathrm{~kg} / \mathrm{ha}$. Os valores médios de MST, de cada período experimental, estiveram acima daquele considerado crítico, de $2.000 \mathrm{~kg} / \mathrm{ha}$, exposto por Minson (1990) como limite mínimo para não restringir o consumo a pasto. Adicionalmente, os valores de disponibilidade de MSV foram superiores aos $1.108 \mathrm{~kg} / \mathrm{ha}$, citados como nãolimitantes ao pastejo seletivo por Euclides et al. (1992), ao analisarem pastagens de Brachiaria decumbens. Segundo esses autores, piquetes de Brachiaria decumbens com uma disponibilidade de $4.262 \mathrm{~kg}$ MS/ha seriam satisfatórios para garantir um pastejo seletivo.

A disponibilidade de forragem favoreceu o pastejo seletivo, não oferecendo limitação à capacidade seletiva dos animais em todo o período experimental e possibilitando a maximização do consumo de MS.

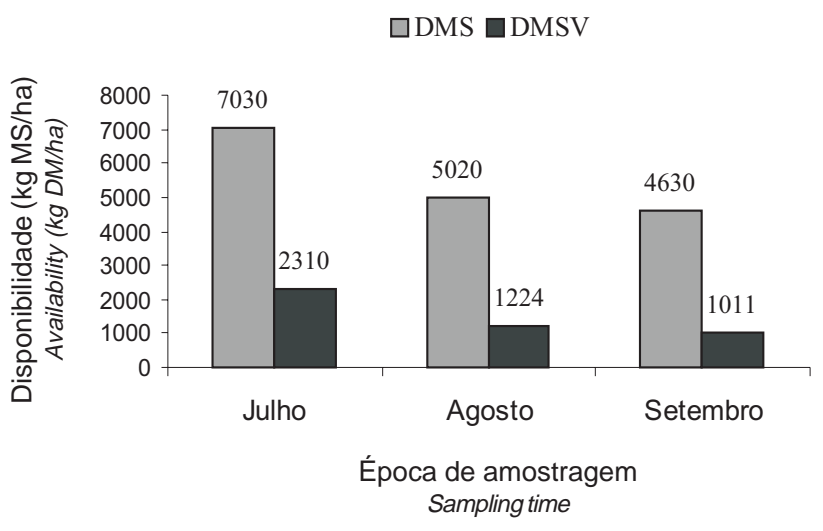

Figura 2 - Disponibilidade média de matéria seca (DMS) e de matéria seca verde (DMSV) da Brachiaria decumbens nos períodos de amostragem.

Figure 2 - Average availability for dry matter (DM) and green dry matter (GDM) of Brachiaria decumbens in sampling periods. 
Apenas $39,5 \%$ dos $5.560 \mathrm{~kg}$ de MS/ha médios disponíveis para os animais foram constituídos de MSV, componente mais procurado pelos animais em pastejo, principalmente no período da seca. Este fato pode ser comprovado pela queda observada na disponibilidade de $\mathrm{MSV}$, de $2.310 \mathrm{~kg} / \mathrm{ha}$ no início do experimento para $1.011 \mathrm{~g} / \mathrm{ha}$ em setembro, demonstrando o comportamento do animal em selecionar uma dieta de melhor valor nutritivo.

Na Tabela 1, são apresentados os teores médios de MS, PB, EE e MM para os diferentes métodos de amostragem. Menores valores de MS $(\mathrm{P}<0,05)$ foram observados para a extrusa, em decorrência da contaminação por saliva. A SMP e a DT também apresentaram diferenças $(\mathrm{P}<0,05)$ quanto ao teor de MS. O maior valor encontrado para a DT se deve ao fato de o pasto estar diferido, apresentando cerca de $60,5 \%$ de material morto.

Não houve diferença $(\mathrm{P}>0,05)$ entre os valores de PB para SMP e extrusa, sendo que a DT apresentou o menor valor $(\mathrm{P}<0,05)$. Inferências contrárias foram observadas por Hafley et al. (1993) e Lopes et al. (1996), que registraram maior teor de PB nas amostras de extrusa em comparação à SMP. O maior valor numérico de PB encontrado na extrusa pode ser explicado principalmente pela contaminação de nitrogênio na saliva, mas possivelmente inclui a capacidade dos animais em selecionar uma dieta de melhor qualidade. Avaliando Brachiaria decumbens no período da seca, Gomes Jr. (2000) verificou diferenças de 6,76 e 3,96\% de PB nas coletas de extrusa e SMP, respectivamente. Avaliando a Brachiaria decumbens, em condições similares às deste trabalho, Santos et al. (2004) encontrou teor médio de $6,35 \%$ de PB para a extrusa, valor próximo aos obtidos nesta pesquisa.

A extrusa e a SMP apresentaram semelhança $(\mathrm{P}>0,05)$ para os teores de EE, que diferiram $(\mathrm{P}<0,05)$ da DT. Goes et al. (2003) avaliando o capim TannerGrass, no período das chuvas, não observaram diferenças para o teor de EE entre a extrusa, SMP e a DT. Entretanto, Detmann et al. (1999) registraram valores de EE superiores para a SMP ao avaliarem a Brachiaria decumbens no período das águas.

A extrusa apresentou teores de MM superiores $(\mathrm{P}<0,05)$ aos de SMP e de DT. O maior valor de MM observado para a extrusa está de acordo com os reportados por Detmann et al. (1999) e são decorrentes da contaminação por saliva. Segundo McManus (1981) citado por Euclides et al. (1992), quando se deseja quantificar a composição mineral de um alimento, este não deve ser amostrado via extrusa, em razão de sua contaminação por saliva.

Os teores médios encontrados para CT, CNF, FDN, FDNcp, FDA, FDAi, lignina e DIVMS encontram-se na Tabela 2. Houve semelhança $(\mathrm{P}>0,05)$ entre a SMP e extrusa, com exceção para os CT, com valores superiores $(\mathrm{P}<0,05)$ aos encontrados para DT, sugerindo que a SMP seria uma amostra próxima àquela selecionada pelo animal em pastejo, no caso, representado pela extrusa.

Os teores de FDN, FDNcp, FDA, FDAi e lignina, nas amostras de $\mathrm{DT}$, foram superiores $(\mathrm{P}<0,05)$ àque-

Tabela 1 - Médias e coeficientes de variação para os teores médios de matéria seca (MS), proteína bruta $(\mathrm{PB})$, extrato etéreo (EE) e matéria mineral (MM) para os diferentes métodos de amostragem

Table 1 - Means and coefficients of variation (CV) for average contents of dry matter (DM), crude protein $(C P)$, ether extract $(E E)$ and mineral matter $(M M)$ from the different sampling

\begin{tabular}{lcccc}
\hline & \multicolumn{3}{c}{$\begin{array}{c}\text { Métodos de amostragem } \\
\text { Sampling methods }\end{array}$} \\
\cline { 2 - 4 } Item $^{1}$ & DT $(T H)^{2}$ & SMP $(H P S)^{3}$ & Extrusa & CV $(\%)$ \\
\hline MS $(D M)-\%$ & $82,56^{\mathrm{a}}$ & $72,39^{\mathrm{b}}$ & $14,20^{\mathrm{c}}$ & 17,74 \\
$\mathrm{~PB}(C P)^{4}$ & $3,81^{\mathrm{b}}$ & $5,60^{\mathrm{a}}$ & $6,50^{\mathrm{a}}$ & 14,20 \\
$\mathrm{EE}^{4}$ & $1,23^{\mathrm{b}}$ & $2,80^{\mathrm{a}}$ & $2,30^{\mathrm{a}}$ & 14,36 \\
$\mathrm{MM}^{4}$ & $6,94^{\mathrm{b}}$ & $7,40^{\mathrm{b}}$ & $11,40^{\mathrm{a}}$ & 10,54 \\
\hline
\end{tabular}

1 Médias, na linha, seguidas por letras distintas, diferem $(P<0,05)$ pelo teste SNK.

2 DT = disponibilidade total.

3 SMP = dimulação manual de pastejo.

$4 \%$ MS.

1 Means, within a row, followed by different letters are different $(P<.05)$ by SNK test.

$2 \mathrm{TH}=$ total harvesting.

3 HPS = hand plucking sample.

$4 \% D M$. 
les obtidos pela extrusa e SMP, porém inferiores $(\mathrm{P}<0,05)$ aos teores de CNF obtidos pela extrusa e SMP. De fato, quando a forragem disponível aos animais é constituída por perfilhos fisiologicamente maduros, como neste estudo, há predominância destes constituintes, que têm influência negativa sobre o valor nutritivo da forragem.

Os valores semelhantes de FDAi obtidos na extrusa e SMP possibilitam a utilização de qualquer um dos métodos de coleta para estimar quantativamente o consumo de matéria seca pelos animais.

Os menores valores $(\mathrm{P}<0,05)$ de DIVMS para a DT refletem a alta concentração de material lignificado, reforçando o conceito do pastejo seletivo, no qual as folhas são preferidas em relação aos colmos e material morto (Carvalho et al., 2001). Portanto, o método da DT não estaria representando a dieta normalmente consumida pelo animal em pastejo. Para os métodos extrusa e SMP, os valores encontrados para a DIVMS foram semelhantes $(\mathrm{P}>0,05)$, com média de $58,25 \%$, bastante superior à de $37,45 \%$ da DT. Kabeya et al. (2000), Goes et al. (2003) e Gomes Jr. (2000) também encontraram semelhanças para a DIVMS da extrusa e da SMP, o que demonstra a capacidade de seleção dos bovinos, observando-se maiores valores de DIVMS das amostras de extrusa e SMP em relação à DT.

Tabela 2 - Médias e coeficientes de variação para os teores médios de carboidratos totais (CT) e não-fibrosos (CNF), fibra em detergente neutro (FDN), fibra em detergente neutro isenta de cinzas e de proteína (FDNcp), fibra em detergente ácido (FDA), fibra em detergente ácido indigestível (FDAi), lignina e digestibilidade in vitro da matéria seca (DIVMS) para os diferentes métodos de amostragem

Table 2 - Means and coefficient of variation (CV) for average contents of total (TC) and non-fibrous carbohydrates (NFC), neutral detergent fiber (NDF), neutral detergent fiber corrected for ash and protein (NDFap), acid detergent fiber (ADF), insoluble acid detergent fiber (iADF), lignin and in vitro dry matter digestibility (IVDMD) from the different sampling methods

\begin{tabular}{lccrr}
\hline & \multicolumn{3}{c}{$\begin{array}{c}\text { Métodos de coleta } \\
\text { Sampling methods }\end{array}$} \\
\cline { 2 - 4 } Item $^{1}$ & DT $(T H)^{2}$ & SMP $(H P S)^{3}$ & Extrusa & CV $(\%)$ \\
\hline CT $(T C)^{4}$ & $88,03^{\mathrm{a}}$ & $85,20^{\mathrm{b}}$ & $79,80^{\mathrm{c}}$ & 1,67 \\
$\mathrm{CNF}(\text { NFC })^{4}$ & $8,88^{\mathrm{b}}$ & $12,79^{\mathrm{a}}$ & $14,10^{\mathrm{a}}$ & 17,32 \\
FDN $(\text { NDF })^{4}$ & $83,24^{\mathrm{a}}$ & $71,87^{\mathrm{b}}$ & $71,70^{\mathrm{b}}$ & 2,74 \\
FDNcp $(\text { NDFap })^{4}$ & $79,15^{\mathrm{a}}$ & $72,41^{\mathrm{b}}$ & $65,70^{\mathrm{b}}$ & 3,55 \\
FDA $(\text { ADF })^{4}$ & $46,21^{\mathrm{a}}$ & $38,70^{\mathrm{b}}$ & $39,50^{\mathrm{b}}$ & 4,67 \\
FDAi $(\text { ADFi })^{4}$ & $30,10^{\mathrm{a}}$ & $20,33^{\mathrm{b}}$ & $18,00^{\mathrm{b}}$ & 7,54 \\
Lignina $(\text { Lignin })^{4}$ & $9,90^{\mathrm{a}}$ & $7,63^{\mathrm{b}}$ & $7,60^{\mathrm{b}}$ & 4,38 \\
DIVMS $($ IVDMD $)$ & $37,45^{\mathrm{b}}$ & $57,07^{\mathrm{a}}$ & $59,43^{\mathrm{a}}$ & 2,43 \\
\hline
\end{tabular}

1 Médias, na linha, seguidas por letras distintas, diferem $(P<0,05)$ pelo teste SNK.

2 DT = disponibilidade total.

3 SMP = simulação manual de pastejo.

$4 \%$ MS.

1 Means, within a row, followed by different letters are different $(P<.05)$ by SNK test.

$2 \mathrm{TH}=$ total harvesting.

3 HPS $=$ hand plucking sample.

$4 \% D M$.

\section{Conclusões}

As análises bromatológicas demonstraram que a metodologia da simulação manual de pastejo possibilita uma estimativa aceitável da forragem selecionada por animais em regime de pastejo. Por outro lado, a coleta de amostras com base na disponibilidade total não representa a dieta selecionada pelo animal, pois superestima o conteúdo fibroso e subestima os teores de proteína bruta do pasto.

\section{Literatura Citada}

CARVALHO, P.C.F.; RIBEIRO FILHO, H.M.N; POLI, C.H.E.C. et al. Importância da estrutura da pastagem na ingestão e seleção de dietas pelo animal em pastejo. In: REUNIÃO ANUAL DA SOCIEDADE BRASILEIRA DEZOOTECNIA, 38, Piracicaba. Anais... Piracicaba: SBZ, 2001. (CD-ROM). COCHRAN, R.C.; ADAMS, D.C.; WALLACE, J.D. et al. Predicting digestibility of different diets with internal markers: Evaluation of four potential markers. Journal of Animal Science, v.63, n.5, p.1476-1483, 1986. 
DETMANN, E.; PAULINO, M.F.P.; ZERVOUDAKIS, J.T. et al. Avaliação qualitativa de dois métodos de amostragem de dieta em pastagens de capim braquiária (Brachiaria decumbens Stapf). In: REUNIÃO ANUAL DA SOCIEDADE BRASILEIRA DE ZOOTECNIA, 1999, Porto Alegre. Anais... Porto Alegre: 1999 (CD-ROM - Nutrição de Ruminantes).

DE VRIES, M.F.W. Estimating forage intake and quality in grazing cattle: consideration of the hand-plucking method. Journal of Range Management, v.48, p.370-375, 1995

EUCLIDES, V.P.B.; MACEDO, M.C.M.; OLIVEIRA, M.P. Avaliação de diferentes métodos para se estimar o valor nutritivo de forragens sob pastejo. Revista Brasileira de Zootecnia, v.21, n.4, p.691-702, 1992.

FORBES, J.M. Voluntary feed intake. In: FORBES, J.M.; FRANCE, J. (Eds.) Quantitative aspects of ruminant digestion and metabolism. Cambridge: University Press, 1993. p.479-494.

GOES, R.H.T.B.; MANCIO, A.B.; LANA, R.P. et al. Avaliação da pastagem de capim Tanner-Grass (Brachiaria arrecta), por três diferentes métodos de amostragem. Revista Brasileira de Zootecnia, v.32, n.1, p.64-69, 2003.

GOMES JR., P. Composição químico-bromatológica da Brachiaria decumbens e desenvolvimento de novilhos em recria suplementados durante a seca. Viçosa, MG: Universidade Federal de Viçosa, 2000. 51p. Dissertação (Mestrado em Zootecnia) - Universidade Federal de Viçosa, 2000.

GOMIDE, J.A.; QUEIROZ, D.S. Valor alimentício das Brachiarias. In: SIMPÓSIO SOBRE MANEJO DA PASTAGEM, 11., 1994, Piracicaba. Anais... Piracicaba: Fundação de Estudos Agrários Luiz de Queiroz, 1994. p.223-248.

HAFLEY, J.L.; ANDERSON, B.E.; KLOPFENSTEIN, T.J. Supplementation of growing cattle grazing warm-season grass with proteins of various ruminal degradabilities. Journal of Animal Science, v.71, n.2, p.522-529, 1993.

JONES, R.J.; LASCANO, C.E. Oesophageal fistulated cattle can give unreliable estimates of the proposition of legume in diets of resident animals grazing tropical pastures. Grass and Forage Science, v.47, p.128-132, 1992.

JOHNSON, A.D. Sample preparation and chemical analysis of vegetation. In: MANETJE, L. t' (Ed.) Measurement of grassland vegetation and animal production. Aberustwyth: Commonwealth Agricultural Bureaux, 1978. p.96-102.

KABEYA, K.S.; PAULINO, M.F.; VALADARES FILHO, S.C. et al. Frações de carboidratos e estimativas das taxas específicas de degradação da Brachiaria brizantha em diferentes métodos de amostragem. In: REUNIÃO ANUAL DA SOCIEDADE BRASILEIRA DE ZOOTECNIA, 37., 2000, Viçosa, MG. Anais...Viçosa: 2000. (CD-ROM - Nutrição de Ruminantes).

KIESLING, H.E.; NELSON, A.B.; HERBEL,C.H. Chemical composition of Tobosa grass collected by hand-plucking systems and esophageal fistulated steers. Journal of Range Management, v.22, n.1, p.155-159, 1969.

LOPES, F.C.F.; AROEIRA, L.J.M.; MALDONADO, V.H. et al. Avaliação qualitativa de dois métodos de amostragem em pastagens de capim-elefante (Pennisetum purpureum Schum.). Revista Argentina Producción Animal, v.16, p.256 (supl. 1), 1996.
McMENIMAN, N.P. Methods of estimating intake of grazing animals. In: REUNIÃO ANUAL DA SOCIEDADE BRASILEIRA DE ZOOTECNIA, 34., Juiz de fora, 1997. Anais... Juiz de Fora: Sociedade Brasileira de Zotoecnia, 1997. p.131168.

MINSON, D.J.; STOBBS, T.H.; HEGARTY, M.P. et al. Measuring the nutritive value of pasture plants. In: SHAW, N.H.; BRYAN, W.W. (Eds.) Tropical pasture research. Oxford: CAB International, 1976. p.308-338.

MINSON, D.J. Forage in ruminant nutrition. Academic Press: New York, 1990. 483p.

MORAES, E.H.B.K.; PAULINO, M.F.; VALADARES FILHO, S.C. et al. Níveis de uréia em suplementos múltiplos para terminação de novilhos mestiços em pastejo no período da seca: consumo. In: REUNIÃO ANUAL DA SOCIEDADE BRASILEIRA DE ZOOTECNIA, 40., 2003, Santa Maria. Anais... Santa Maria: 2003. (CD-ROM - Nutrição de Ruminantes).

NOLLER, C.H.; NASCIMETO JR, D.; QUEIROZ, D.S. Exigências nutricionais de animais em pastejo. In: SIMPÓSIO SOBRE O MANEJO DA PASTAGEM, 13., 1997, Piracicaba. Anais... Piracicaba: Fundação de Estudos Agrários Luiz de Queiroz, 1997. p.319-352.

PEDREIRA, C.G.S. Avanços metodológicos na avaliação de pastagens. In: REUNIÃO ANUAL DA SOCIEDADE BRASILEIRA DE ZOOTECNIA, 39., 2002, Recife. Anais de Palestras... Recife: 2002. (CD-ROM).

PAULINO, M.F.; ACEDO, T.S.; SALES, M.F.L. et al. Suplementação como estratégia de manejo das pastagens. In: SIMPÓSIO SOBRE VOLUMOSOS NA PRODUÇÃO DE RUMINANTES: VALOR ALIMENTÍCIO DE FORRAGEM, 2003, Jaboticabal. Anais... Jaboticabal: Universidade Estadual Paulista, 2003. p.87-100.

SANTOS, E.D.G.; PAULINO, M.F.; QUEIROZ, D.S. et al. Avaliação de pastagem diferida de Brachiaria decumbens Stapf.: 1. Características químico-bromatológicas da forragem durante a seca. Revista Brasileira de Zootecnia, v.31, n.1, p.203-213, 2004.

SILVA, D.J.; QUEIROZ, A.C. Análise de alimentos: métodos químicos e biológicos. 3.ed. Viçosa, MG: Universidade Federal de Viçosa, 2002. 165p.

SNIFFEN, C.J.; O'CONNOR, J.D.; Van SOEST, P.J. et al. A net carbohydrate and protein system for evaluating cattle diets: II. Carbohydrate and protein availability. Journal of Animal Science, v.70, n.11, p.3562-3577, 1992.

TILLEY, J.M.A.; TERRY, R.A. A two-stage technique for the in vitro digestion of forage crops. Journal of British Grassland Society, v.18, p.104-111, 1963.

UNIVERSIDADE FEDERAL DE VIÇOSA - SAEG, UFV. Sistema de análises estatísticas e genéticas. Versão 8.1. Viçosa, MG: 2000. (Manual do usuário).

Van SOEST, P.J.; ROBERTSON, J.B.; LEWIS, B.A. Methods for dietary fiber, and nonstarch polysaccharides in relation to animal nutrition. Journal of Dairy Science, v.74, n.10, p.3583-3597, 1991. 